\title{
EFFECT OF ACUTE LOW OXYGEN EXPOSURE ON THE PROLIFERATION RATE, VIABILITY AND GENE EXPRESSION OF C2C12 MYOBLASTS IN \\ VITRO
}

BY

\section{JACK V SHARKEY}

School of Sport, Exercise and Health Sciences

Loughborough University 


\begin{abstract}
INTRODUCTION Changes in the oxygen concentration of cellular microenvironments play a significant role in regulating cell function during muscle regeneration. Generally, most in-vitro cell culture experiments have been carried out in atmospheric conditions with $21 \% \mathrm{O}_{2}$, which compared to the actual micro-environment of mature skeletal muscle of between $1 \%$ and $10 \%$ pO2 is extremely hyperoxic (Li et al, 2007). Culturing skeletal muscle cells in vitro within their typical physiologically hypoxic environment in situ (2-10\% pO2) has been shown to increase proliferation rate, reduce apoptosis and increase multiple MRF gene expressions, compared to culturing in a normoxic environment $\left(21 \% \mathrm{O}_{2}\right)$. However, chronic exposure $(>24 \mathrm{hr})$ to a semi-severe hypoxic environment $\left(\leq 5 \% \mathrm{O}_{2}\right)$ can lead to a decrease in cell proliferation and differentiation (Chakravarthy et al, 2001). The effects of acute hypoxic exposure (24 h) has limited research and could be important in understanding the effects of hypoxia on skeletal muscle during brief exposures such as those observed within intermittent hypoxic training programmes. The purpose of this work was to examine the role of acute hypoxia $(24 \mathrm{~h})$ on $\mathrm{C}_{2} \mathrm{C}_{12}$ proliferation and relevant gene expression in $2 \mathrm{D}$ culture. METHODS $\mathrm{C}_{2} \mathrm{C}_{12}$ mouse myoblast cells were seeded into six well plates. The cells were maintained in DMEM with $20 \%$ FCS. $\mathrm{C}_{2} \mathrm{C}_{12}$ myoblasts were either exposed to $21 \%$ or $5 \% \mathrm{O}_{2}$. The effects of acute hypoxic exposure (24hours) at different time points during the proliferative phase of myogenesis, rather than chronic exposure, on cell proliferation, cellular viability and myogenic regulatory factor gene expression was examined. At 24, 48, 72 and 96 hours RNA was extracted using the Trizol ${ }^{\circledR}$ method and mRNA expression of myogenic regulatory factors, myoD, myf5 and myogenin were detected using the 2- $\Delta \Delta \mathrm{CT}$ method. Cell counts and cell viability were also quantified RESULTS No significant difference was found between cells cultured in normoxic conditions $(21 \%)$ and those that were exposed to low oxygen conditions for 24 hours at various time points over a 96 hour culture period, with regards to proliferation rate, cell viability, and myogenic regulatory gene expression (Myf5, MyoD and Myogenin). DISCUSSION The effect of acute low oxygen exposure lasting 24hours appears to not be insufficient in having an effect on the proliferation rate, viability or transcription factor expression of $\mathrm{C} 2 \mathrm{C} 12$ cells during the proliferative phase of myogenesis.
\end{abstract}




\section{$\underline{\text { INTRODUCTION }}$}

Within human tissue, oxygen concentrations are considerably less than the $21 \% \mathrm{O}_{2}$ concentrations found in ambient air, and is termed physiological hypoxia. Typically the partial pressure of oxygen $\left(\mathrm{pO}_{2}\right)$ of human tissue lies between $1 \%$ and $14 \%$ (Stamati, Mudera and Cheema, 2011), with considerable local and regional variations (Figure.1). Within the tissues' own microenvironment, changes in oxygen concentrations play a significant role in regulating cell function, and can have effects including maintenance of stem cell pluripotency, angiogenesis, stem cell differentiation, ATP regulation, and pH regulation. (Stamati, Tamati and Mudera, 2011; Weidemann et al, 2008; Lin et al, 2008).

Satellite cells, are muscle-resident stem cells found below the basal lamina adhered to the muscle fibres (Mauro, 1961). Activation of the quiescent satellite cells is brought about in order to regenerate or repair muscle tissue, which is generally due to a stress induced change in their micro-environment, caused by either weight bearing exercise or injury (Kuang \& Rudnicki, 2008; Miller, Schaefer \& Dominov, 1999; Bischoff and Heintz, 1994). Once activated the stem cells undergo proliferation at which point they are known as adult myoblasts. These then differentiate and fuse into multinucleated skeletal muscle fibres (Le Grand \& Rudnicki, 2007, Kuang et al, 2008). This process, known as myogenesis, is dependent on several transcription factors known as myogenic regulatory factors (MRFs); MyoD, Myf5, Myogenin and MRF4 (Majmundar et al, 2012; Cornelsion et al, 2000; Charge \& Rudnicki, 2004, Yablonka-Reuveni and Rivera, 1994). Prior to activation the quiescent satellite cells express the transcription factor $\mathrm{PAX}_{7}$ (Le Grand \& Rudnicki, 2007). Once activated within 12hours there is a rapid up-regulation 
of $M y o D$ and $M y f 5$, along with $P A X_{7}$ and all possess distinct functional roles (Majmndar et al, 2012). Myf5 is a regulator for muscle progenitor proliferation, whilst $M y o D$ is necessary for the consequent differentiation of these precursors (Majmundar et al, 2012). During the proliferation phase of myogenesis, there is co-expression of both $M y o D$ and Myf5 (Cornelison \& Wold, 1997).

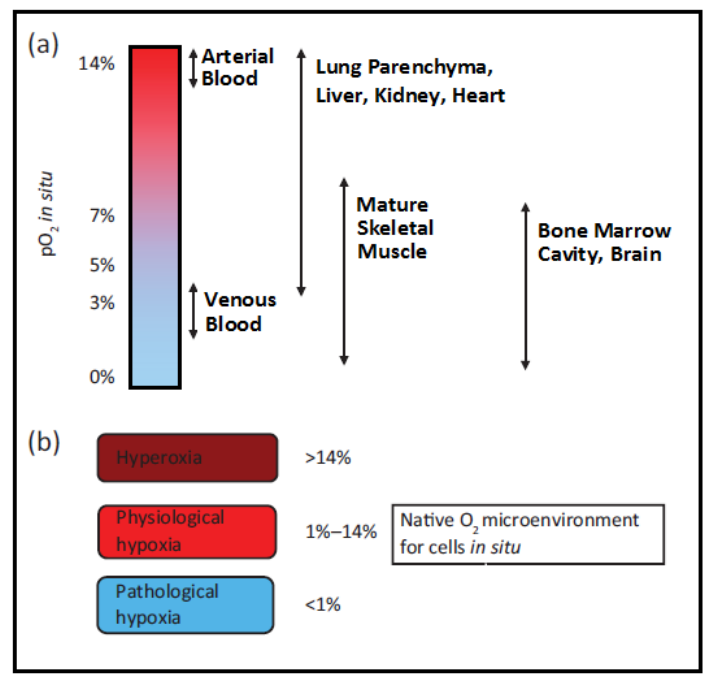

Figure 1. (a) Values of micro-environmental $\mathrm{O}_{2}$ found in tissues in situ (b) $\mathrm{O}_{2}$ micro-environment for cells residing within different tissues in mammalian body. $\bullet$ Image adapted from Stamati, Mudera \& Cheema (2011); values taken from Warkerntin (2002), Das, Jahr \& Van Osch (2010) \& Li, Zhu, Chen \& Fan (2007).

With the co-existence of $M y o D$ and $M y f 5$, the genes activate the upregulation of Myogenin. MyoD and Myogenin stimulate the myoblasts to undergo terminal differentiation and fusion into myofibers through the activation of genes in mature muscle such as the Myosin heavy chain (Kuang et al, 2008; Yablonka-Reuveni and Rivera 1994). Subsequently $P 21$, a cell cycle arrest protein, is activated, causing an irreversible exit of the myoblast from the cell cycle. It is also known that MRF4 is actively expressed during the differentiation phase and continues to be released once 
newly regenerated myofibers have been fused, indicating that MRF4 has a role in myofiber maturation. (Zhou and Bornemann, 2001) (Figure.2).

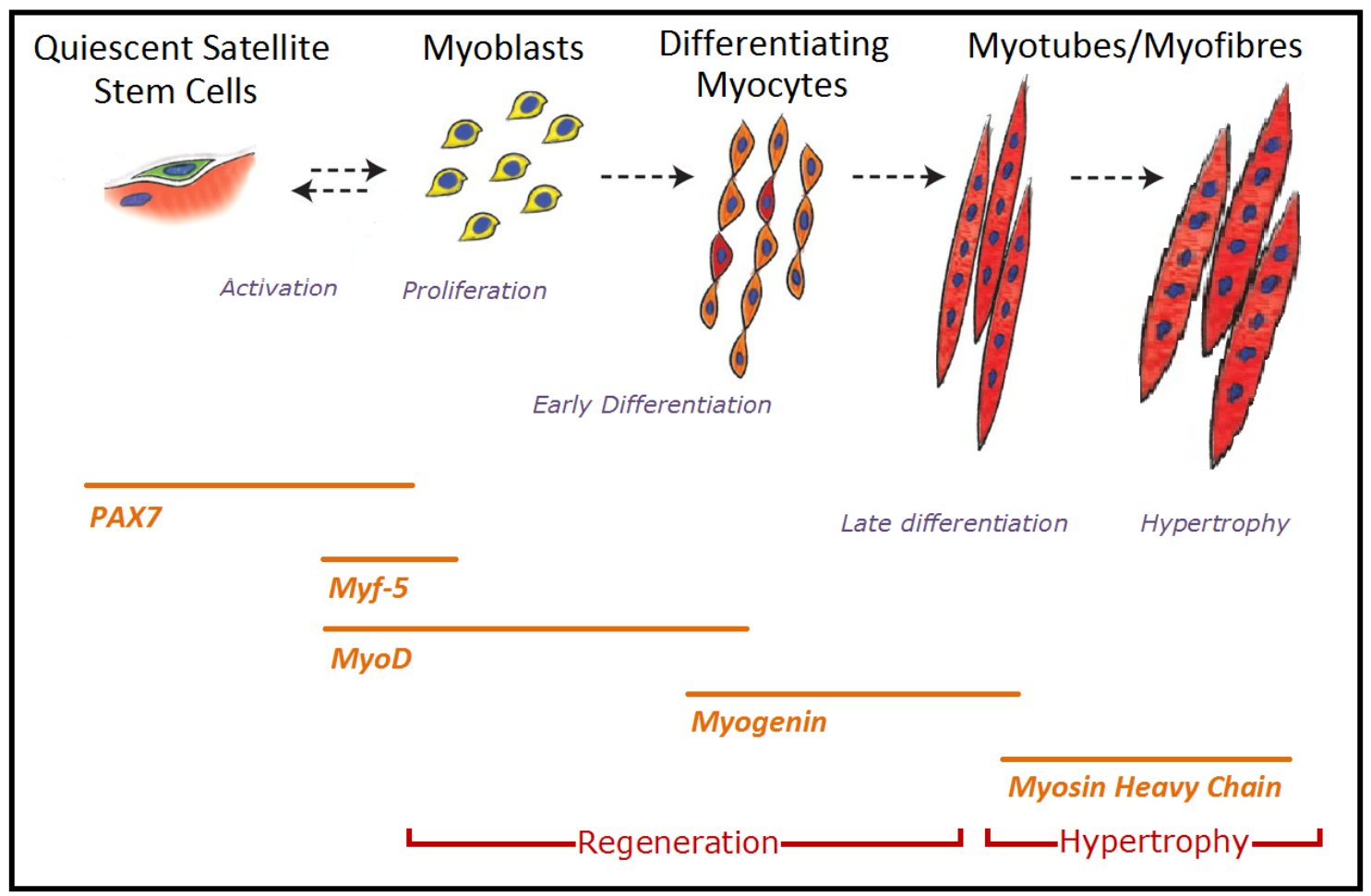

Figure 2. (a) Schematic of the stages of myogenesis from quiescent satellite cells to myotube formaton and hypertrophy, along with an indication of the time periods at which various genes are expressed $\bullet$ Image adapted from Bentzinger, Wang \& Rudnicki (2012)

The local microenvironment, otherwise known as the stem cell niche, within the skeletal muscle that accommodates quiescent satellite cells is generally between $1 \%$ and $10 \%$ $\mathrm{pO}_{2}$ (Li 2007). Stress induced changes of the oxygen concentration caused by trauma or weight bearing exercise is believed to be one of the main physiological regulators of satellite cell activity and activation, indicating manipulation of $\mathrm{pO} 2$ exposure could be an affective means of improving muscle regeneration (Lui et al, 2012). There is some physiological data of local interstitial $\mathrm{pO}_{2}$ which has been evaluated using a number of techniques, including oxygen microelectrodes, microspectrophotometry, proton 
madnetic resonance spectroscopy and phosphorescence quenching (Pittman, 2011., Poole et al, 2011). However, the exact systemic environment of satellite cells that precisely regulates quiescence or activation, and self-renewal or differentiation, is largely unknown (Lui, 2012).

Generally, most in-vitro cell culture experiments have been carried out in atmospheric conditions with $21 \% \mathrm{O}_{2}$, which compared to the actual micro-environment of mature skeletal muscle of between $1 \%$ and $10 \%$ pO2 is extremely hyperoxic (Li et al, 2007). To develop a better understanding of the molecular mechanisms behind myogenesis and the cell cycle in-vitro, it has been suggested that experiments should be performed in environmentally low conditions that mimic the normal physiological environments. Research in this area has shown that satellite cells cultured in physiologically hypoxic conditions $\left(2-10 \% \mathrm{O}_{2}\right)$ result in a significant increase in proliferation rate, improved survival of mature fibers, decreased satellite cell adipogenisis, promoted myogenesis and larger myotube formations, compared to cultures grown in 21\% pO2 (Zhao et al, 2003; Chakravarthy et al, 2001). It is also noted that the signalling pathways responsible for regulating stem cell proliferation and differentiation are impacted by the $\mathrm{O} 2$ concentration of the surrounding micro-environment. With regards to myogenesis and MRF expression, during the proliferation phase there is a significant up-regulation of MyoD, Myf5 and Myogenin when C2C12 murine cells are cultured in 6\% $\mathrm{O} 2$ conditions compared to $20 \%$. (Csete et al 2001). 
When the $\mathrm{pO}_{2}$ is dropped below $2 \%$ within the microenvironment, also known as pathological hypoxia, the expression of differentiation markers (MyoD, Myf5, and Myogenin) begin to be inhibited, along with the inhibition of quiescient satellite cell activation and of multinucleated myotube formation (Roy et al, 2003). Furthermore there is a notable reduction in satellite cell proliferation and increased apoptosis (Sato et al, 2011; Di Carlo et al, 2004). The inhibition of myogenic differentiation is found to be through accelerated $M y o D$ degredation by the ubiquitin-proteasome pathway (DiCarlo et al, 2004).

In general the atmospheric conditions used in traditional muscle cells culture in vitro is largely ignored, and recent experiments have found culturing cells in more physiologically atmospheric conditions may be more beneficial for myogenesis and lead to a better understanding of the molecular processes behind skeletal muscle repair and regeneration (Reecy et al, 2003). Whether acute exposure of low oxygen on muscular regeneration is as beneficial as chronic exposure is yet to be examined, and may play a vital role in the use of using the manipulation of $\mathrm{O}_{2}$ concentrations in improving muscle self renewal, damage repair and treating regenerative disease (Li et al, 2007). The aim of the following study is to further support the ever-growing research that culturing cells in a physiologically hypoxic environment is optimal for myogenesis compared to an ambient atmosphere. Specifically the following study aims to establish the effects of twenty-four hours of acute physiological hypoxia $\left(5 \% \mathrm{pO}_{2}\right)$ during the proliferative phase of myogenesis, including proliferation rate, cellular viability and myogenic regulatory factor gene expression of proliferating $\mathrm{C} 2 \mathrm{C} 12$ myoblasts. 


\section{METHOD}

\section{Cell Culture}

C2C12 murine myoblasts were provided by the Health Protection Agency Culture Collections (HPA Cultures, Salisbury, UK). Three separate lines of C2C12's within $1.8 \mathrm{ml}$ vial's were removed from liquid nitrogen and quickly defrosted. The cells were plated at 12500 cells $/ \mathrm{cm}^{2}$ in T80 culture flasks $\left(80 \mathrm{~cm}^{2}\right.$ Flasks, NUNC, Denmark) and suspended in $20 \mathrm{ml}$ of growth medium (GM) consisting of high glucose Dulbecco's Modified Eagle's Medium (DMEM) (Sigma-Aldrich, Haverhill, UK), 20\% Foetal Bovine Serum (FBS) (PAA, Paisley, UK), and 1\% penicillin/streptomycin (SigmaAldrich, Haverhill, UK). Once suspended the cells were kept within a humidified incubator (Heracell 240i $\mathrm{CO}_{2}$ Incubator, Thermo Fisher Scientific Inc, USA) where conditions were kept constant at $37^{\circ} \mathrm{C}$ in a normoxic environment $\left(21 \% \mathrm{O}_{2}, 5 \% \mathrm{CO}_{2}, 74 \%\right.$ $\mathrm{N}_{2}$ ). Growth medium was replaced every 48 hours, and once cells had reached $80 \%$ confluence, cells were passaged.

To ensure the line of $\mathrm{C} 2 \mathrm{C} 12$ cells used within this experiment could undergo differentiation, a T80 flask was seeded at a density of 12500 cells $/ \mathrm{cm}^{2}$ and cultured for 96 hours until $100 \%$ confluent. Once confluency had been achieved the GM was replaced with differentiation media (DM) to promote myoblast fusion $(2 \% \mathrm{FCS}, 1 \% \mathrm{P} / \mathrm{S}$, and DMEM) (Sigma-Aldrich, Haverhill, UK) and left to culture for a further 48 hours. The cells were then fixed and stained for immunocytochemistry (Figure.3) 


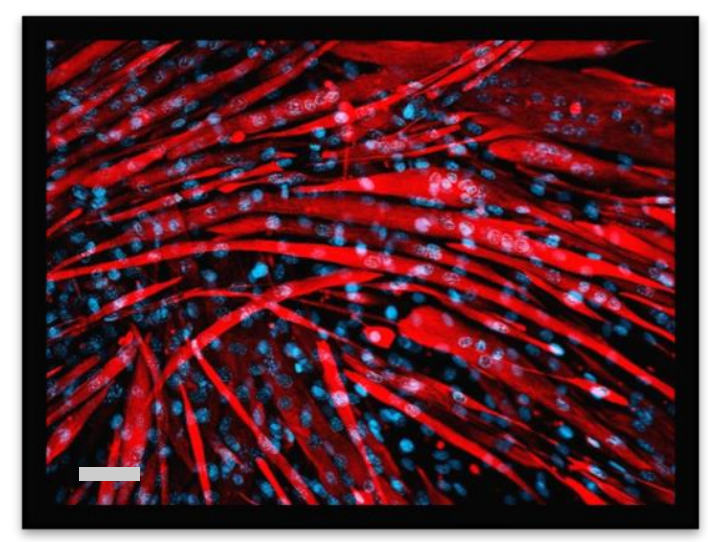

Figure.3 Murine C2C12's in culture immunostained for desmin (red) with a DAPI nuclear counter stain (blue). Note the formation of myotubes indicating the line of $\mathrm{C} 2 \mathrm{C} 12$ 's used were able to undergo fusion into multinucleated myotubes, Scale bar $=20 \mu \mathrm{m}$.

Once a passage number of seven was attained the cells were split and seeded into eight, six well plates (NUNC A/S, Denmark) in $2 \mathrm{ml}$ of Growth medium at a density of 1500 cells $/ \mathrm{cm}^{2}$. The plate layout consisted of three wells for $\mathrm{qPCR}$, one well for immunocytochemistry containing three $13 \mathrm{~mm}$ sterile glass coverslips, one well for cell counts and microscopy, and one well for checking the oxygen concentration within the microenvironment of the C2C12's. (Figure.4)

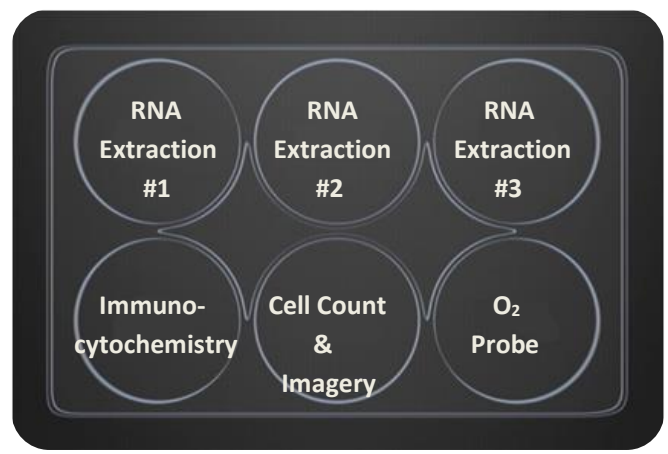

Figure.4 Representation of the six well plate layout.

Cells were sampled for RNA and immunostaining every 24 hours upto a 96 hour timepoint. During this time the $\mathrm{C} 2 \mathrm{C} 12$ cells were cultured in a humidified incubator 
(Heracell 240i $\mathrm{CO}_{2}$ Incubator, Thermo Fisher Scientific Inc, USA) at $37^{\circ} \mathrm{C}$ under normoxic conditions $\left(21 \% \mathrm{pO}_{2}\right)$. The hypoxic treatment involved an acute exposure of hypoxia during the final twenty-four hours of culture under what would be expected to be a physiological hypoxic condition $\left(5 \% \mathrm{pO}_{2}\right)$. This was achieved by placing the cells within a SANYO $\mathrm{CO}_{2} / \mathrm{O}_{2}$ hypoxic incubator (MCO-5M, Panasonic, USA) at $37^{\circ} \mathrm{C}(5 \%$ $\mathrm{O}_{2}, 5 \% \mathrm{CO}_{2}, 90 \% \mathrm{~N}_{2}$ ). Once the plates were removed from their incubators, they were sampled immediately. A schematic of the experimental design is shown in Figure.5. The GM was refreshed within the plates every twenty-four hours, prior to being placed in either the normoxic or hypoxic incubators. The experiment was repeated three times using three separate lines of C2C12's.

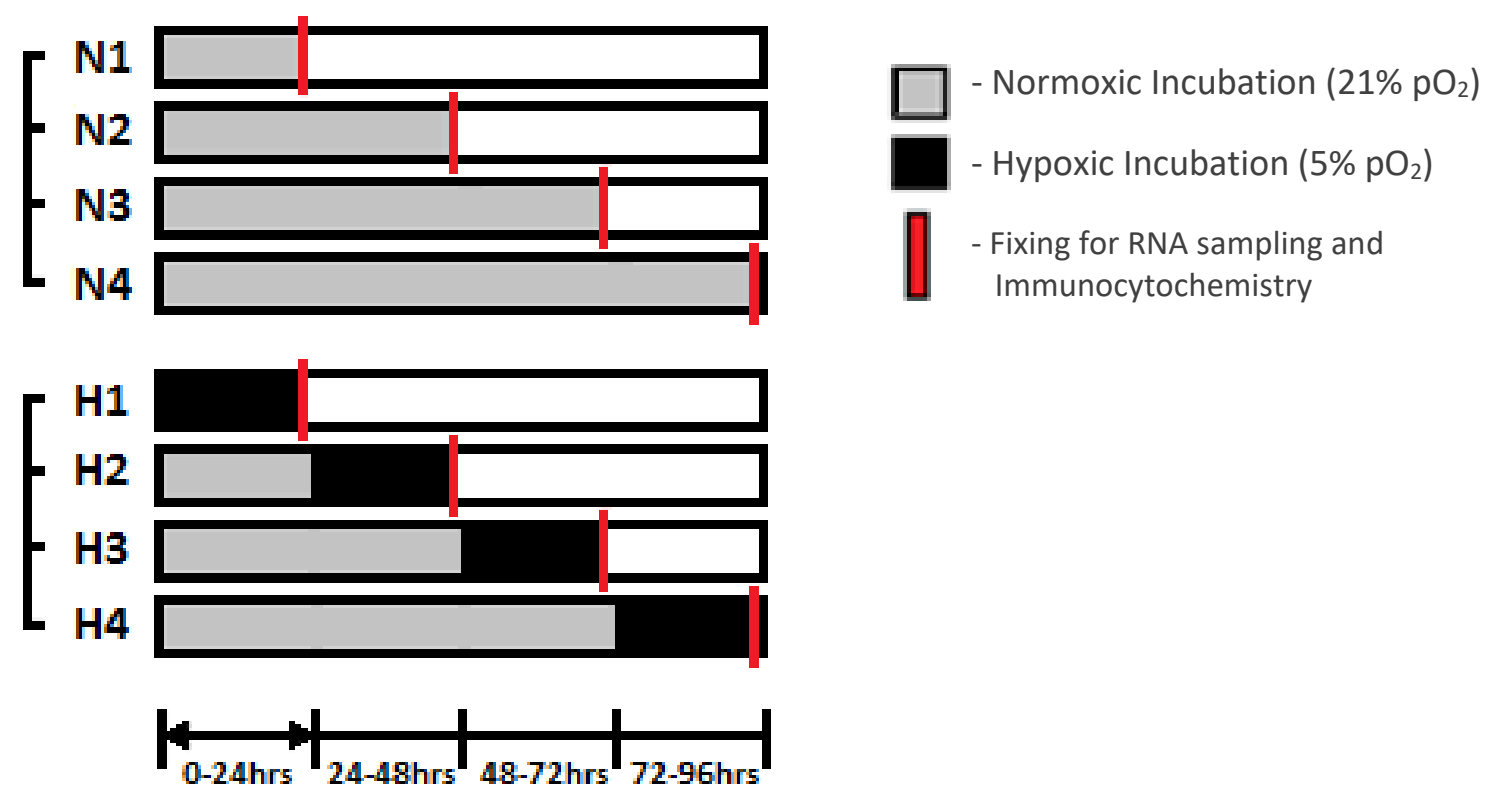

Figure.5 Schematic diagram of the study design $\mathrm{N}=$ Normoxic Exposure $\mathrm{H}=$ Normoxic with $24 \mathrm{hr}$ hypoxic exposure.

To ensure the microenvironment in which the cells were cultured was at a concentration of $5 \% \mathrm{O}_{2}$ during the hypoxic exposure, a dip-type oxygen microelectrode (MI-730 $\mathrm{O}_{2}$ 
Microelectrode, Microelectrodes Inc, Bedford, UK) along with PowerLab 4/25T with LabChart Software (ADinstruments, New Zealand) was used. The probe was calibrated according to manufacture instructions and placed within the GM of one of the $\mathrm{C} 2 \mathrm{C} 12$ inhabited wells through a drilled hole on the roof of the plate. Oxygen concentrations were checked at the end of each twenty-four hour time period for 3 minutes to ensure a constant $5 \%$ concentration of oxygen had been reached.

\section{Cell Counts and Microscopy}

The hypoxic and normoxic exposed cells were removed from their incubators and analysed using an LED microscope (Leica DM IL LED, Leica Microsystems, Wetzler, Germany) at twenty-four hour time points throughout the four day culture period and ten images were taken within the designated well for imagery. A cell count of viable cells was performed using a heamoctyometer with Trypan blue exclusion. This was achieved by removing the GM from the monolayer of cells and adding $1 \mathrm{ml}$ of Trypsin. Warm Phosphate Buffered Saline solution (PBS) was not placed on the cells so a count of the non-viable adhered cells could be carried out. Once the Trypsin was added, the plate was incubated at $37^{\circ} \mathrm{C}$ for five minutes with occasional disturbance to displace the cells from the wells. Using the LED microscope the cells were checked for detachment followed by adding $2 \mathrm{ml}$ of growth media (GM) to neutralise the effect of the Trypsin. If cells were still confluent, the serum was carefully triturated using a pipette or passed through a filter.

\section{Immunocytochemistry}

Within one of the wells of the six well plates, C2C12 cells were cultured on three $13 \mathrm{~mm}$ sterile glass coverslips (Sigma-Aldrich, Haverhill, UK). At the end of the designated 
exposure time in either the normoxic or hypoxic chamber, cells were fixed using icecold fixative solution consisting of one part methanol, to one part acetone $(1 \mathrm{ml})$. The monolayer of cells were permeabilized using a solution of 1x TRIS buffered saline solution (TBS) along with 5\% normal goat serum (GS) and $0.2 \%$ Triton X-100 for 30 minutes. Following a thorough wash with TBS, a rabbit monoclonal anti-mouse desmin primary antibody (Sigma-Aldrich, Haverhill, UK) diluted 1 in 200 in TBS solution with $2 \%$ GS and $0.2 \%$ Triton $\mathrm{X}-100$ was added to the cells and left at room temperature for two hours. A thorough TBS wash ensued before being treated with a goat anti-rabbit TRITC secondary antibody (Sigma-Aldrich, Haverhill, UK) diluted 1 in 200 in TBS with $2 \%$ GS and $0.2 \%$ Triton X-100 and left for one hour in room temperature with no light exposure. Finally, following a TBS wash, a fluorescent minor-groove DNA binding probe DAPI (4,6-diamidino-2-phenylindole; 1.0ng/ml; Sigma Aldrich, Haverhill, UK) was added to act as a nuclear stain and left for 10 minutes. Once completed the coverslips were thoroughly washed using TBS, dried, before being mounted on glass microscope slides using MOWIOL mounting medium. Examination was carried out by immunoflouresent microscopy using a Leica DM2500 microscope and Leica software LAC V3.7 (Leica Microsystems, Wetzler, Germany).

\section{RNA Extraction and Quantitative PCR}

Levels of proliferation and the onset of differentiation of the 2D culture was determined by quantitative PCR (qPCR) analysis of MyoD, Myf5, and Myogenin expression. Total RNA was extracted from the cells using the TRIzol $^{\circledR}$ reagent protocol according to manufacturer instructions (Invitrogen). qPCR was run using the Stratagene Mx3005P PCR System (Applied Biosystems, Warrington UK). The PCR reaction mixture $(10 \mu 1$ SYBR Green, $0.2 \mu 1 \mathrm{RT}$ mix, $0.15 \mu 1$ forward primer, $0.15 \mu 1$ reverse primer) was created 
for each gene to be analysed in duplicate over a 96 well plate (Applied Biosystems). Of this reaction mix, $10.5 \mu 1$ of solution was added to each well along with $9.5 \mu 1$ of solution containing 70ng of RNA dissolved in RNAse-free water. The plate was incubated at $50^{\circ} \mathrm{C}$ for 10 minutes and $95^{\circ} \mathrm{C}$ for 5 minutes before undergoing 40 cycles of $95^{\circ} \mathrm{C}$ for 10 seconds and $60^{\circ} \mathrm{C}$ for 30 seconds, a thermal profile specifically designed by Applied Biosystems for use with assays designed according to Applied Biosystems assay design guidelines. The primer sequences used are presented in Table.1.

A cycle threshold $\left(\mathrm{C}_{\mathrm{T}}\right)$ was defined as the fractional cycle number at which the fluorescence generated by cleavage of the probe exceeded a fixed threshold above the baseline. A Comparative $\mathrm{C}_{\mathrm{T}}$ method outlined by Applied Biosystems, was used to quantitate the amount of each target gene present. The mean $\mathrm{C}_{\mathrm{T}}$ values of the duplicate samples from each sample was determined and normalised to RPII, which acted as the endogenous housekeeping gene. Relative quantitation of mRNA expression was calculated using the ddCT method, using the $2^{-\Delta \Delta C t}$ formula (Livak \& Schmittgen, 2001).

\begin{tabular}{ll}
\hline Gene & Primer Sequence \\
\hline$M y o G$ & F: CCAACTGAGATTGTCTGTC \\
(GenBank NM_153798.2) & R: GGTGTTAGCCTTATGTGAAT \\
$M y o D$ & F: CATTCCAACCCACAGAAC \\
(GenBank NM_010866) & R: GGCGATAGAAGCTCCATA \\
Myf5 & F: CGTATTATGAACTCTCTC \\
(GenBank NM_008656) & R: CAAGACAGTATTTACAAC \\
RPII-B(Housekeeper Gene) & F: GGTCAGAAGGGAACTTGTGGTAT \\
(GenBank NM_031189.2) & R: GCATCATTAAATGGAGTAGCGTC \\
\hline
\end{tabular}

Table.1. Primer sequences used for PCR analysis. MyoG - Myogenin Factor 4, MyoD - Myogenic Differentiation 1, Myf5 - Myogenic Factor 5. 


\section{Statistical Analysis}

A mixed measures ANOVA was performed to assess differences across treatments (Hypoxia and Normoxia) and across time (24h, 48h, 72h, and 96h). Paired $t$-tests were used to compare between Normoxia and Hypoxia treatment differences at individual time points. Significance was accepted when $P<0.05$. Statistical tests were conducted using SPSS version 19.0 (SPSS, Inc, Chicago, Illinois, USA). Data are reported as mean $\pm \mathrm{SD}$.

\section{$\underline{\text { RESULTS }}$}

\section{Cell Counts and Viability}

The Heamocytometer assay with Trypan blue exclusion showed no significant difference in proliferation rates between cells cultured under normoxia or acute hypoxia at any of the twenty four hour time points (Figure.6). However, collectively over time, there was a notable increase in Total Cell Count with significant differences between time points. There was no significant difference in cell counts between twenty-four hours and forty-eight hours, although cell count increased significantly over time between 48 and 72 hours $(\mathrm{P}<0.026)$, and between 48 and 96 hours $(\mathrm{P}<0.003)$. There was a notable rise in cell counts between seventy-two hours and ninety-six hours of culturing but this was found to be non-significant $(\mathrm{P}<0.126)$. 


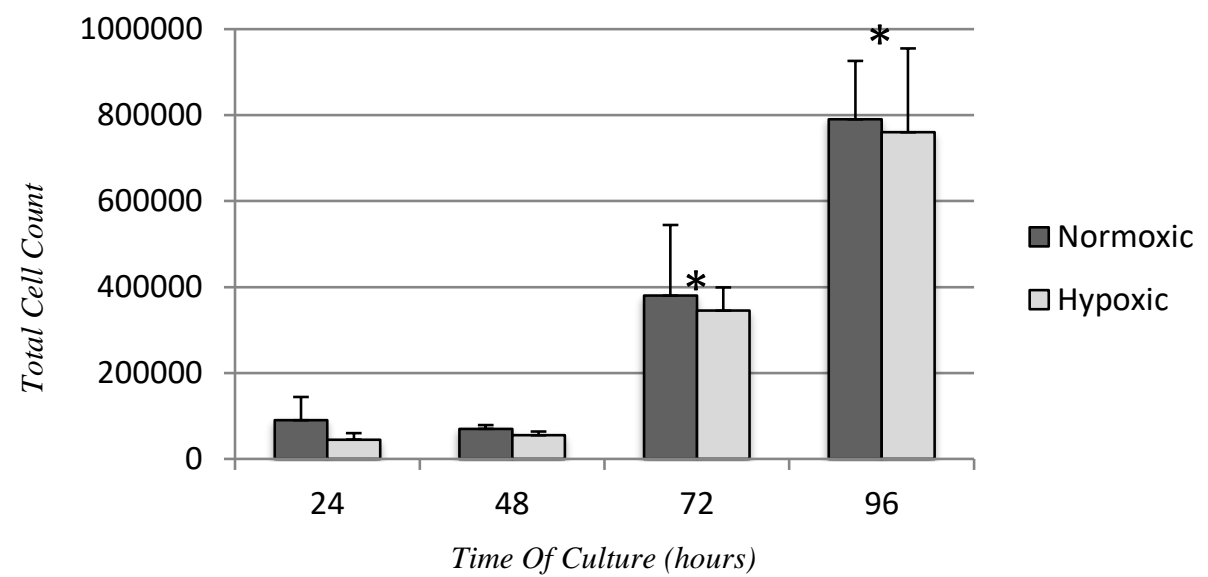

Figure.6 Total cell count of adhered cells, taken every 24 hours over a 96 hour period in vitro, as determined by a haemocytometer. Values expressed as mean \pm standard deviation. No significant differences were observed between Normoxic and Hypoxic exposure at any time point with total cell counts $(\mathrm{P}>0.05)$.

The percentage of viable cells within the total cell count did not differ significantly at any of the twenty four hour time points between cells cultured under normoxia or acute hypoxia. Although there is a possible trend towards a reduction in cell viability after forty-eight hours before recovering at seventy-two and ninety-six hours. Over time, cell viability did not differ between any of the twenty-four hour time points over the ninetysix hour culture period (Figure.7)

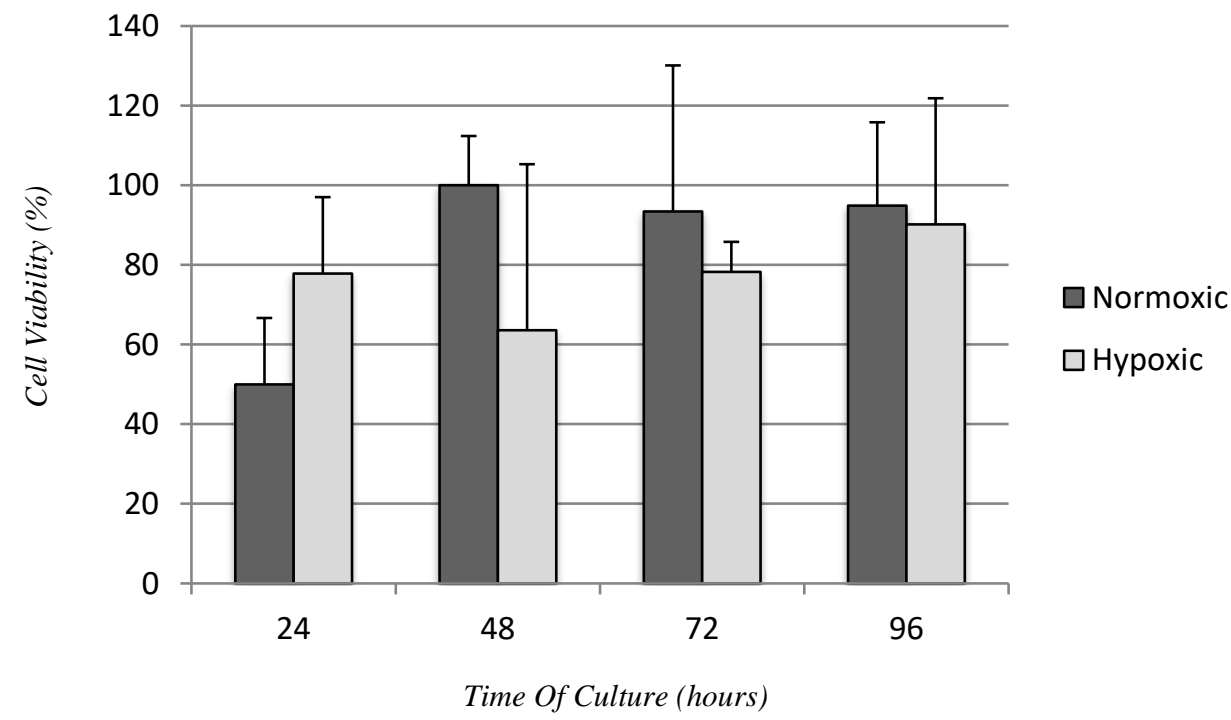

Figure.7 Percentage of viable cells adhered to coverslips taken every 24 hours over a 96 hour period in vitro, as determined by haemocytometer and Trypan blue exclusion. Hypoxic treatment involved acute hypoxic exposure of $5 \% \mathrm{O}_{2}$ during the final 24 hours of culturing. Values expressed as mean \pm standard deviation. . 


\section{Quantitative PCR Analysis}

Quantative PCR analysis found no significant difference in relative $M y f 5, M y o D$ and Myogenin mRNA expression levels between the two exposure conditions of normoxia or acute hypoxia following twenty-four, forty-eight, seventy-two and ninety-six hours of culturing $(\mathrm{P}>0,05)$ (Figure.8). Concerning changes in mRNA expression levels over time, no differences were found between any of the time points when analysing $M y f 5$ and $M y o D$, however there does appear to be a trend toward Myf5 expression increasing over time in both conditions. Myogenin mRNA expression levels following twenty-four hours of culturing were significantly higher than those expressed following forty-eight hours $(\mathrm{P}<0.06)$, seventy-two $(\mathrm{P}<0.011)$ and ninety-six $(\mathrm{P}<0.014)$ hours of culturing with both treatments.

Myf5 mRNA Expression

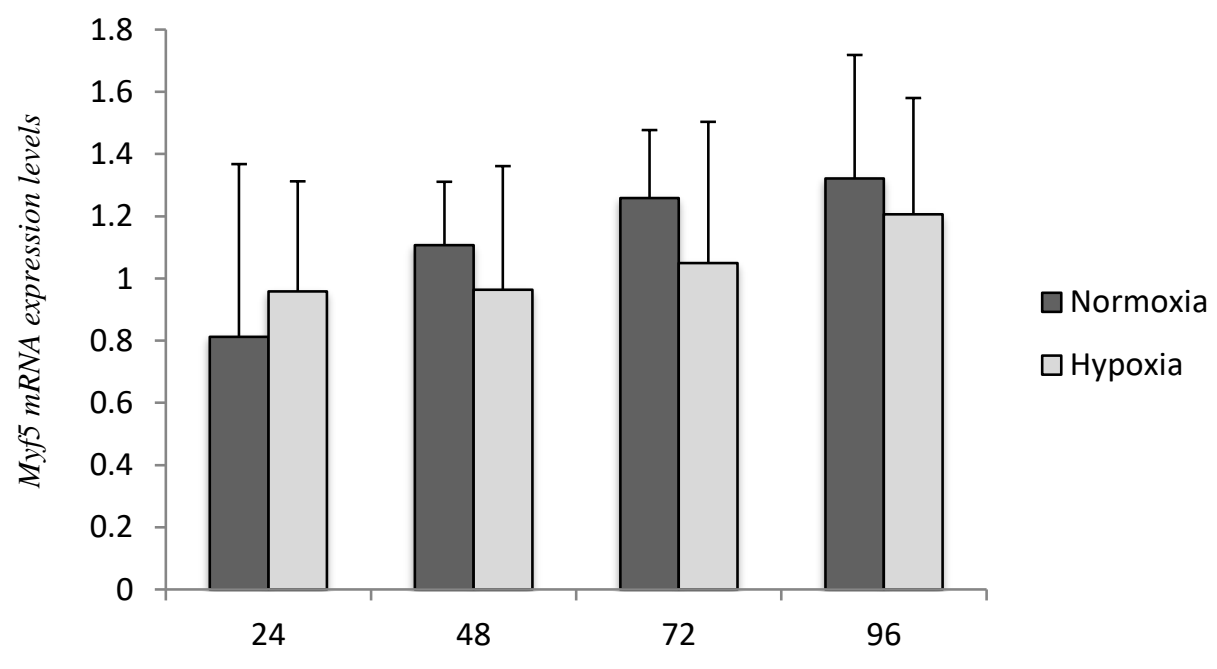

Time Of Culture (hours) 


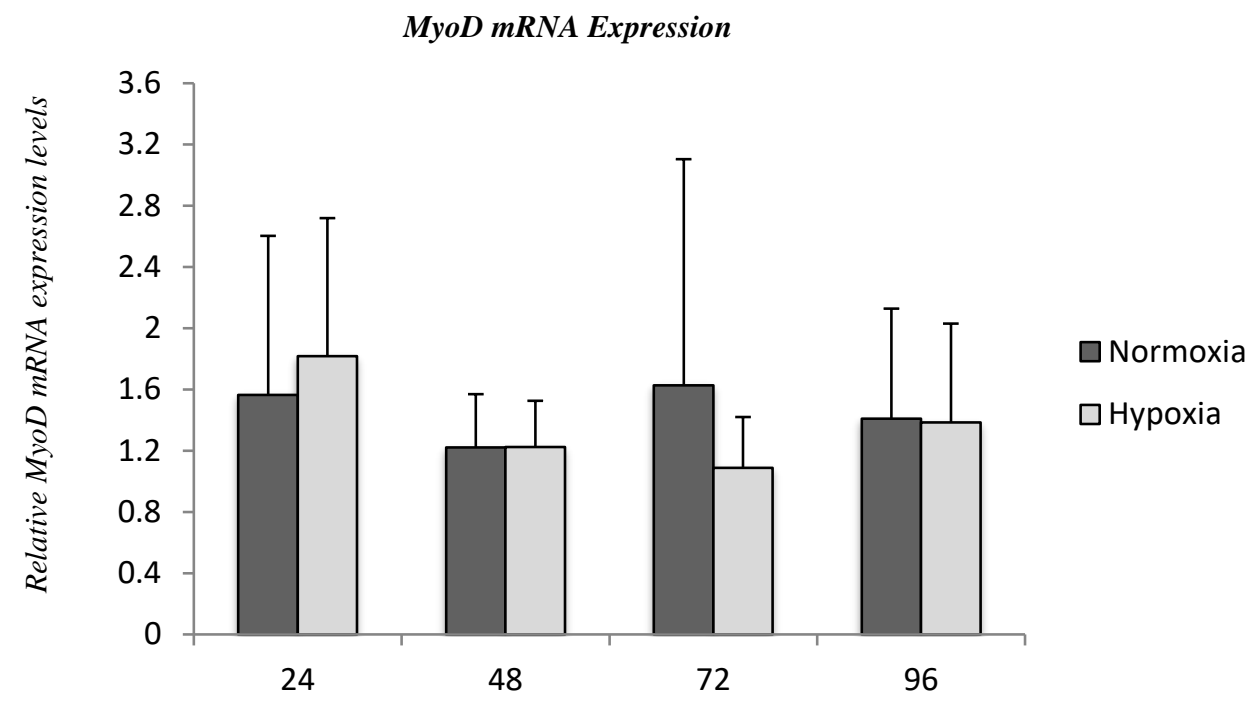

Time Of Culture (hours)

\section{Myogenin mRNA Expression}

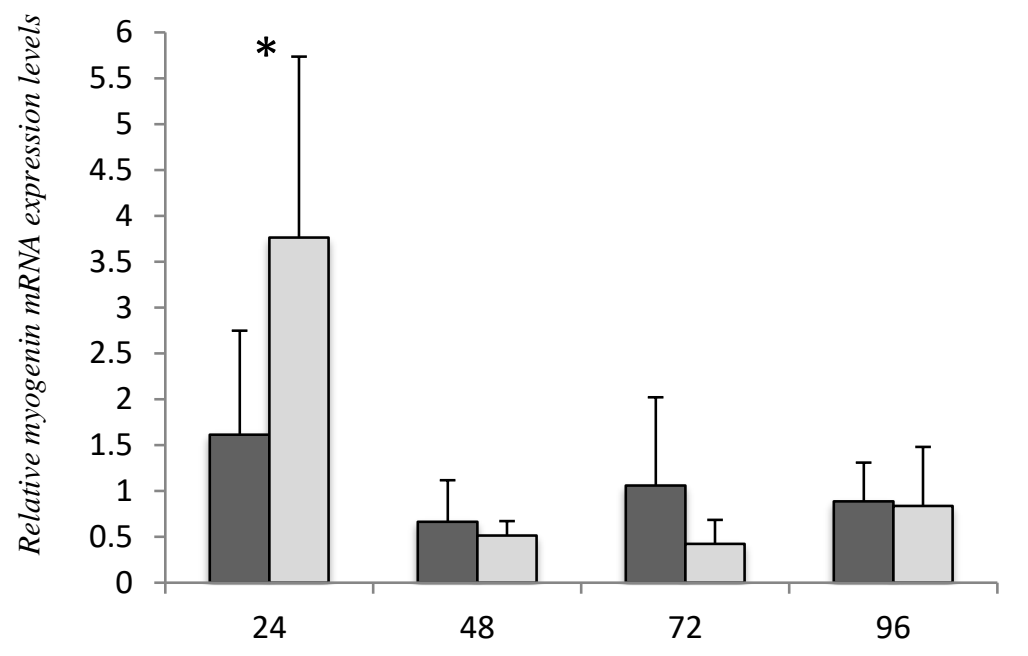

Time Of Culture (hours)

Figure.8 Relative Myf5, MyoD and Myogenin mRNA expression levels from 2D C2C12 cultures, taken every 24 hours over a 96 hour period in vitro, as determined by qPCR. CT values were normalised to an internal housekeeping gene (RPII) and expressed relative to levels recorded following 24 hours of culture in normoxic conditions $n=6$. Significant difference between timepoints at $* \mathrm{P}<0.05$. Values expressed as mean \pm standard deviation. . No significant differences were observed between Normoxic and Hypoxic exposure at any time point with all three genes. $(\mathrm{P}>0.05)$ 


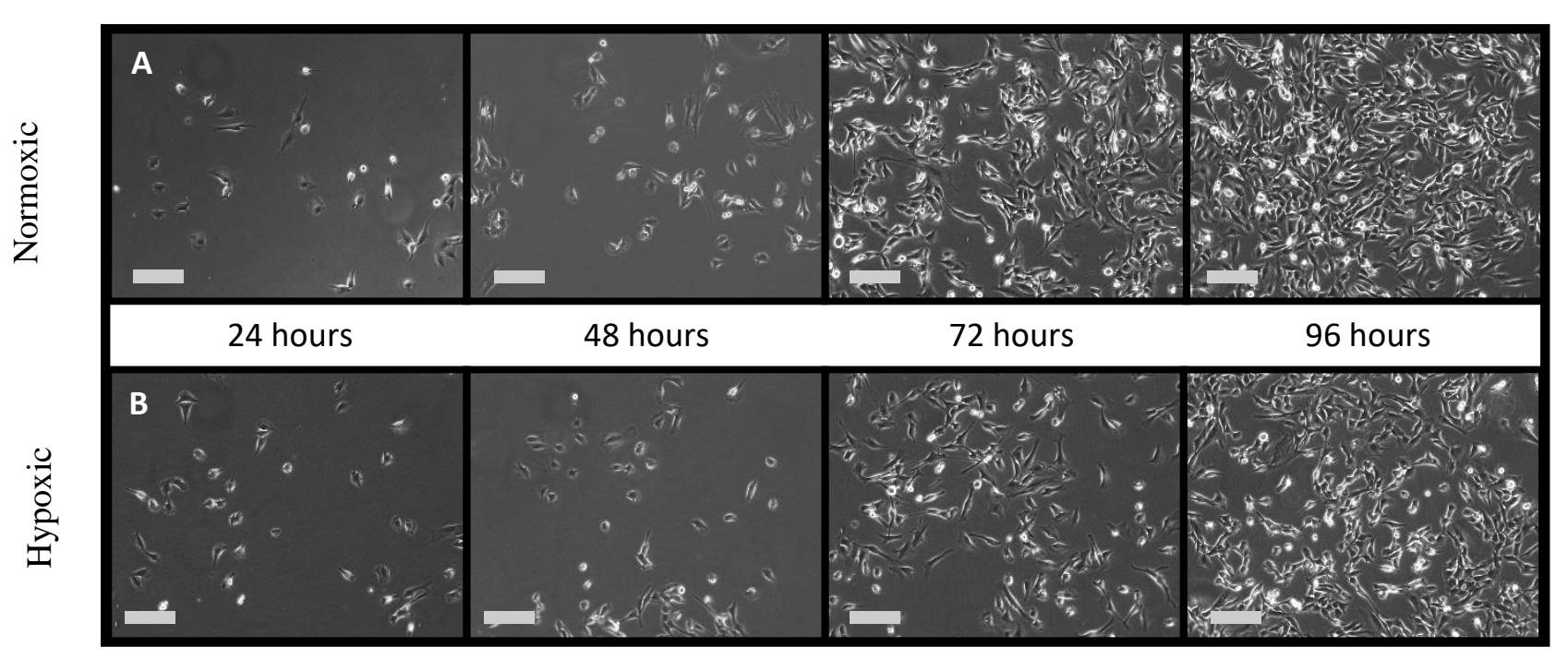

Figure.9 Murine C2C12's in vitro. C2C12 cells were cultured in GM for a total of four days. Cells were fixed every 24 hours. (A) Cells incubated under normoxic conditions $\left(20 \% \mathrm{O}_{2}\right)(\mathrm{B})$ Cells incubated under normoxic conditions $(20 \%$ $\mathrm{O}_{2}$ ) and exposed to acute hypoxic exposure $\left(5 \% \mathrm{O}_{2}\right)$ during the final 24 hours of culturing. Images selected randomly from a selection of ten. Scale bar $=20 \mu \mathrm{m}$.

\section{DISCUSSION}

The aim of this study was to establish whether acute low oxygen exposure influences the proliferation rate, viability and MRF expression of $\mathrm{C} 2 \mathrm{C} 12$ cells in vitro. This study has shown that $\mathrm{C} 2 \mathrm{C} 12$ myoblasts are unaffected following acute exposure to a low oxygen environment during the proliferative phase of myogenesis. The hypoxic exposure which involved exposure of $5 \% \mathrm{O}_{2}$ during the final 24hours of culturing upto and including 96hours of total culture time, elicited no significant change in proliferative rate, cell viability or mRNA expression of Myf5, MyoD and Myogenin compared to cells grown in atmospheric conditions. Further analysis of these images also indicated no myotube formation had occurred following both the normoxic and hypoxic treatments. 
It is generally accepted that most stem cells that are cultivated in lower, physiologic oxygen environments, proliferate more than in $21 \% \mathrm{O}_{2}$ environments (Ramirez, 2011, Csete, 2005; Li et al, 2007). This improvement in proliferative capacity in low oxygen has been found in a variety of stem cells including, murine CNSderived multipotent stem cells (Studer et al, 2000), marrow-derived mesenchymal stem cells (Lennon et al, 2001), and adult murine skeletal muscle satellite cells (Csete et al, 2001; Chakravarthy et al, 2001). Regarding the cultivation of skeletal muscle satellite cells, the increase in proliferative capacity has been found when satellite cells were cultured between $2 \%$ and $10 \% \mathrm{pO}_{2}$. The enhanced proliferation of stem cells in lower oxygen may in part reflect the typical relatively low oxygen microenvironment that the satellite cell are found in vivo which is usually around 2-10\% $\mathrm{pO}_{2}$ (Greenbaum et al, 1997; Richardson, 1998). Although the $\mathrm{C} 2 \mathrm{C} 12$ cells used in this study are a mouse myoblast cell line typically cultivated in atmospheric conditions. Therefore $21 \% \mathrm{O}_{2}$ could be considered normoxic whilst $5 \% \mathrm{O}_{2}$ would be deemed extremely hypoxic for $\mathrm{C} 2 \mathrm{C} 12$ cells. Generally, the increase in proliferation rate elicited is believed to be down to the effect the change in $\mathrm{O}_{2}$ has on the signalling pathways that regulate stem cell proliferation and MRF expression. Specifically chronic low oxygen exposure $\left(2-10 \% \mathrm{pO}_{2}\right)$ has been found to result in a significant up-regulation of MyoD, Myf5 and Myogenin in a number of skeletal muscle cell lines (Yun et al, 2005, Kook et al, 2008, Csete et al 2001).

This experiment found no change in proliferative capacity or MRF expression when cells were cultured in a low oxygen environment, although this is the first experiment of its kind to look at the effects of acute hypoxic exposure (24hours) at different time points during the proliferative phase of myogenesis, rather than chronic exposure. The 
design study aimed to establish whether acute exposure is effective at eliciting a change in proliferative capacity or MRF expression and if so then at which stage of the proliferative phase of myogenesis should it be used. Sato et al (2011) looked at the effect of culturing $\mathrm{C} 2 \mathrm{C} 12$ 's continuously for 122 hours at $2 \%, 5 \%$ and $10 \%$ oxygen levels. Interestingly they found that growth rate of the cells in the hypoxic environments was the same as cells under normal conditions for upto 2 days after plating before growth rate increased (Sato et al, 2011). Lui et al (2012) found that the initial 48hours of culturing primary murine myoblasts in $1 \% \mathrm{pO}_{2}$ affected myoblast fate decision by promoting self-renewal and inhibiting differentiation, but overall cell proliferation was not affected. However, earlier research by Csete et al (2001) did still find a significantly improved rate of proliferation of satellite cells found on cultured single muscle fibres following as little as 24 hours of hypoxic exposure at $6 \% \mathrm{O}_{2}$. Nevertheless, the results of this study with that of recent literature, do tend to indicate 24hours of exposure to a low, physiological oxygen environment may not be an adequate exposure time to induce an effect on cell proliferation rate. It is still unclear whether the hypoxic condition used in the present study reflects the drop in intramyocellular oxygen pressure induced by exercise, muscular damage or hypoxic exposure (Sato et al, 2011; Hoppeler et al, 2003), however when using manipulation of $\mathrm{O}_{2}$ concentrations in improving muscle self renewal for damage repair or treating regenerative disease, it may be possible that exposure times must be longer than 24hours to be effective.

Concerning the effects acute low oxygen exposure has on MRF expression, this study found no difference over time with regards to Myf5, MyoD and Myogenin expression. Aswell as chronic low oxygen exposure being known to increase expression of all these 
transcription factors, short term exposure has been shown to upregulate the myogenic regulatory factors $M y f 5$ and $M y o D$ when at $6 \% \mathrm{O}_{2}$ (Csete et al, 2001). When culturing cells in more extreme hypoxic conditions $\left(2-0.1 \% \mathrm{pO}_{2}\right)$, there appears to be a down regulation of Myf5 and MyoD expression (Sato et al, 2011; Koning et al, 2011, Lui et al 2012). As no research has yet looked at the effects acute exposure at $5 \% \mathrm{O}_{2}$ has on these specific MRF's, it may be possible that $5 \% \mathrm{O}_{2}$ is the cut off point between which hypoxia either starts having an up-regulatory or down-regulatory effect on Myf5 and $M y o D$ and expression. Concerning myogenin, its expression has been shown not to differ significantly by cells under normoxic or hypoxic environment for upto 96hours after induction (Sato et al, 2011) supporting our findings and indicating as to why we did not see a significant change in myogenin after such a short hypoxic exposure. However myogenin, a transcription factor that stimulates myoblasts to undergo terminal differentiation and fusion into myofibers, typically does not undergo up-regulation until both $M y f 5$ and $M y o D$ are coexpressed, usually around 96 hours after plating of C2C12's (Rudnicki et al, 2008; Sato et al, 2011, Yablonka-Reuveni and Rivera 1994). The findings of this study found myogenin expression was significantly higher following 24hours of culturing in both normoxic and hypoxic conditions, before a rapid downregulation and no change between 48-96hours of culturing (Figure.8). Explanations for this occurrence are challenging.

Regarding cell viability, this study found that 24 hours of acute physiologically hypoxic exposure did not influence cell viability during the proliferative phase of C2C12's culturing in vitro. This is in contrast to the research looking at the effects of chronic physiological hypoxic exposure that has found various stem cells undergo significantly 
less apoptosis of cultures in low oxygen than in the traditional $21 \% \mathrm{O}_{2}$ conditions (Erkkila et al, 1999, Csete et al, 2001). Furthermore the usual reduction in apoptosis has been found to lead to the increased yield of cultured stem cells during the proliferative phase of cells cultured within low oxygen conditions (Studer et al, 2000). Specifically looking at murine muscle satellite stem cells, C2C12's undergo significantly less apoptosis in $6 \% \mathrm{O}_{2}$ than in $20 \% \mathrm{O}_{2}$ following 3 days of exposure (Csete et al, 2001). The possible mechanisms suggested for the anti-apoptotic effect of culturing in low oxygen conditions, is that fewer reactive oxygen species are generated in cells cultured in low oxygen conditions, compared to higher oxygen conditions. Specifically primary murine myoblasts cultured in $6 \% \mathrm{pO}_{2}$ generated around $\frac{1}{3}$ fewer reactive oxygen species compared to cells cultured in $20 \%$ oxygen (Csete, 2005). On the contrary Ramires et al (2011) found following three days of culturing in $5 \% \mathrm{pO}_{2}$ there is a significant rise in oxidative stress leading to increased apoptosis. It must be reiterated that these studies looked at the effect of chronic hypoxic exposure, with at least 48hours of exposure. This study used similar oxygen concentrations during the hypoxic exposure, but the exposure time during this study was only 24 hours and deemed acute. Therefore the reason that no difference in cell viability was found, leads to the possible suggestion that acute exposure does not allow for an adequate change in reactive oxygen species concentrations and therefore an effect on cell viability. Research that has looked at the apoptosis of neural stem cells in hypoxic conditions, did not find a significant difference until 72 hours of exposure in 1\%, 2.5\% and 5\% pO2 (Santilli et al, 2010). 
Analysing the techniques used to assess cell viability, it appears the methods used could have been performed more effectively to give a more accurate analysis of cell viability. A heamoctyometer using the Tyrpan blue exclusion method was used for cell counts, yet this would only have been looking at the cells still adhered to the bottom of the six well plate. Although a PBS wash was not performed prior to cell counts to prevent the removal of non-viable cells, the growth medium was removed and any non-adhered cells, most likely the non-viable cells, would not have been accounted for. Therefore an accurate count of the non-viable cells would not have been performed. Future research should aim to include non-adhered cells within the growth medium in the cell counts by centrifuging the removed medium and re-suspending these cells prior to total cell counts being performed, leading to a more accurate account of cell viability and proliferation rates. Independent of this observation, when analysing the cell viability of adhered cells, it can be suggested that the acute hypoxic exposure did not influence the percentage of viable cells as well as the proliferation rate.

It should be noted that the physiologic hypoxic environment in which the cells were cultured $\left(5 \% \mathrm{pO}_{2}\right)$ was regulated using the Sanyo $\mathrm{O}_{2} / \mathrm{CO}_{2}$ Incubator. Although oxygen sensors embedded within the incubator would ensure the atmospheric environment inside were kept at a constant, it is also important to ensure the oxygen tension seen at the level of the tissue culture monolayer is also expressive of a physiologic hypoxic environment. The oxygen tension seen at a cellular level can vary considerably to the level of oxygen that the incubators deliver, and a number of factors can influence this variation, including the depth of medium, the density of cells, and cellular respiration (Csete, 2005; Muschler, Nakamoto \& Griffith, 2004). Within this study to monitor the 
oxygen tension seen by the cells, a hole was drilled into the top of a single well of the plates and a dip-type oxygen microelectrode was placed within the growth medium at the cellular level. This approach to incorporate multiple oxygen sensors embedded at various levels to monitor oxygen tension is a novel approach that is yet to be seen within studies that culture $\mathrm{C} 2 \mathrm{C} 12$ in hypoxic environments. The results indicated that the oxygen tension seen at the cell level was also $5 \% \mathrm{pO}_{2}$ at the end of the twenty-four hour exposure time in the hypoxic incubator and it can be confirmed the cells were exposed to a physiologically hypoxic environment. .

Conversely, it should be noted that due to the fact oxygen tension was only measured at the end of the 24hours of hypoxic exposure within the incubator, a full expression of the change in oxygen tension throughout the twenty-four hour exposure time is not given. Therefore, it cannot be known how long it took the medium to drop to the $5 \% \mathrm{pO}_{2}$ or whether the exposure time differed as the cells became more confluent. Future research, should try to monitor cell level oxygen tension throughout the hypoxic exposure time to establish at which point a $5 \% \mathrm{pO}_{2}$ is attained, and also the probe should be placed within the cells cultured in the normoxic environment to ensure those cells are exposed to a normoxic environment. A further limitation is that although the incubator allowed control of oxygen levels during cultivation, it is impossible to prevent reperfusion of atmospheric conditions when the cells are removed from the incubators before being fixed (Csete, 2005). In order to ensure the cells are exposed to relatively constant levels of oxygen, it would be preferential for cells to be cultured and manipulated in a closed workstation that allows for oxygen and $\mathrm{CO}_{2}$ control. 
Although a considerable amount of work has looked at the effects exercise and altitude have on oxygen concentrations within the body (Howald \& Hoppeler et al, 2003; Hoppeler et al, 2008), it is still unclear whether the hypoxic condition used in the present study reflect the drop in intramyocellular oxygen pressure induced by exercise, altitude or pathological damage (Sato et al, 2011; Hoppeler et al, 2003). Therefore the results of this study may not yet be related to the effects exercise or acute altitude training have on skeletal muscle proliferation rates within humans. Although should intramyocellular oxygen pressures be able to be manipulated, it may be possible to suggest twenty-four hours of exposure at $5 \% \mathrm{O}_{2}$ is inadequate in inducing improved muscular regeneration. That being said, in vitro it can be concluded that the effect of acute low oxygen exposure lasting 24hours appears to have no effect on the proliferation rate, viability or transcription factor expression of $\mathrm{C} 2 \mathrm{C} 12$ 's during the proliferative phase of myogenesis. Future research may wish to use more stringent methods with regards to fixing cells within a hypoxic environment and better controls during counts of cell viability. Furthermore, a look at whether lower concentrations of $\mathrm{O}_{2}$ on the proliferative capacity of $\mathrm{C} 2 \mathrm{C} 12$ 's, aswell as various exposure times is needed to develop a greater understanding of the effects acute hypoxia has on the proliferative phase of myogenesis. 


\section{REFERENCES}

Bentzinger CF, Wang YX, Rudnicki MA (2012) Building muscle: molecular regulation of myogenesis. Cold Spring Harb Perspect Biol 4:10.1101/cshperspect.a008342. doi:10.1101/cshperspect.a008342; 10.1101/cshperspect.a008342

Bischoff R, Heintz C (1994) Enhancement of skeletal muscle regeneration. Dev Dyn 201:41-54. doi:10.1002/aja.1002010105

Chakravarthy MV, Spangenburg EE, Booth FW (2001) Culture in low levels of oxygen enhances in vitro proliferation potential of satellite cells from old skeletal muscles. Cell Mol Life Sci 58:1150-1158

Cornelison DD, Olwin BB, Rudnicki MA, Wold BJ (2000) MyoD(-/-) satellite cells in single-fiber culture are differentiation defective and MRF4 deficient. Dev Biol 224:122137. doi:10.1006/dbio.2000.9682

Cornelison DD, Wold BJ (1997) Single-cell analysis of regulatory gene expression in quiescent and activated mouse skeletal muscle satellite cells. Dev Biol 191:270-283. doi:10.1006/dbio.1997.8721

Csete M (2005) Oxygen in the cultivation of stem cells. Ann N Y Acad Sci 1049:1-8. doi:10.1196/annals.1334.001

Csete M, Walikonis J, Slawny N et al (2001) Oxygen-mediated regulation of skeletal muscle satellite cell proliferation and adipogenesis in culture. J Cell Physiol 189:189196. doi:10.1002/jcp.10016 
Das R, Jahr H, van Osch GJ, Farrell E (2010) The role of hypoxia in bone marrowderived mesenchymal stem cells: considerations for regenerative medicine approaches. Tissue Eng Part B Rev 16:159-168. doi:10.1089/ten.TEB.2009.0296

Di Carlo A, De Mori R, Martelli F, Pompilio G, Capogrossi MC, Germani A (2004) Hypoxia inhibits myogenic differentiation through accelerated MyoD degradation. J Biol Chem 279:16332-16338. doi:10.1074/jbc.M313931200

Erkkila K, Pentikainen V, Wikstrom M, Parvinen M, Dunkel L (1999) Partial oxygen pressure and mitochondrial permeability transition affect germ cell apoptosis in the human testis. J Clin Endocrinol Metab 84:4253-4259

Greenbaum AR, Etherington PJ, Manek S et al (1997) Measurements of oxygenation and perfusion in skeletal muscle using multiple microelectrodes. J Muscle Res Cell Motil 18:149-159

Hoppeler H, Klossner S, Vogt M (2008) Training in hypoxia and its effects on skeletal muscle tissue. Scand J Med Sci Sports 18 Suppl 1:38-49. doi:10.1111/j.16000838.2008.00831.x

Howald H, Hoppeler H (2003) Performing at extreme altitude: muscle cellular and subcellular adaptations. Eur J Appl Physiol 90:360-364. doi:10.1007/s00421-003-08729

Koning M, Werker PM, van Luyn MJ, Harmsen MC (2011) Hypoxia promotes proliferation of human myogenic satellite cells: a potential benefactor in tissue 
engineering of skeletal muscle. Tissue Eng Part A 17:1747-1758. doi:10.1089/ten.tea.2010.0624

Kook SH, Son YO, Lee KY et al (2008) Hypoxia affects positively the proliferation of bovine satellite cells and their myogenic differentiation through up-regulation of MyoD. Cell Biol Int 32:871-878. doi:10.1016/j.cellbi.2008.03.017

Kuang S, Gillespie MA, Rudnicki MA (2008) Niche regulation of muscle satellite cell self-renewal and differentiation. Cell Stem Cell 2:22-31. doi:10.1016/j.stem.2007.12.012

Kuang S, Rudnicki MA (2008) The emerging biology of satellite cells and their therapeutic potential. Trends Mol Med 14:82-91. doi:10.1016/j.molmed.2007.12.004

Kuang S, Rudnicki MA (2008) The emerging biology of satellite cells and their therapeutic potential. Trends Mol Med 14:82-91. doi:10.1016/j.molmed.2007.12.004

Le Grand F, Rudnicki MA (2007) Skeletal muscle satellite cells and adult myogenesis. Curr Opin Cell Biol 19:628-633. doi:10.1016/j.ceb.2007.09.012

Lennon DP, Edmison JM, Caplan AI (2001) Cultivation of rat marrow-derived mesenchymal stem cells in reduced oxygen tension: effects on in vitro and in vivo osteochondrogenesis. J Cell Physiol 187:345-355. doi:10.1002/jcp.1081

Li X, Zhu L, Chen X, Fan M (2007) Effects of hypoxia on proliferation and differentiation of myoblasts. Med Hypotheses 69:629-636. doi:10.1016/j.mehy.2006.12.050 
Li X, Zhu LL, Chen XP, Fan M (2007) Role of HIF signaling pathway involved in effects of hypoxia on proliferation and differentiation of myoblasts. Sheng Li Ke Xue Jin Zhan 38:224-228

Lin Q, Kim Y, Alarcon RM, Yun Z (2008) Oxygen and Cell Fate Decisions. Gene Regul Syst Bio 2:43-51

Liu W, Wen Y, Bi P et al (2012) Hypoxia promotes satellite cell self-renewal and enhances the efficiency of myoblast transplantation. Development 139:2857-2865. doi:10.1242/dev.079665

Livak KJ, Schmittgen TD (2001) Analysis of relative gene expression data using realtime quantitative PCR and the 2(-Delta Delta C(T)) Method. Methods 25:402-408. doi:10.1006/meth.2001.1262

Majmundar AJ, Skuli N, Mesquita RC et al (2012) O(2) regulates skeletal muscle progenitor differentiation through phosphatidylinositol 3-kinase/AKT signaling. Mol Cell Biol 32:36-49. doi:10.1128/MCB.05857-11

Mauro A (1961) Satellite cell of skeletal muscle fibers. J Biophys Biochem Cytol 9:493-495

Miller JB, Schaefer L, Dominov JA (1999) Seeking muscle stem cells. Curr Top Dev Biol 43:191-219

Muschler GF, Nakamoto C, Griffith LG (2004) Engineering principles of clinical cellbased tissue engineering. J Bone Joint Surg Am 86-A:1541-1558 
Pittman RN (2011). Oxygen gradients in the microcirculation. Acta Physiol 202, 311322.

Poole DC, Copp SW, Hirai DM, Much TI (2011) Dynamics of muscle microcirculatory and bloos-myocyte $\mathrm{O}_{2}$ flux during contractions. Acta Physiol 202, 293-310.

Ramirez MA, Pericuesta E, Yanez-Mo M, Palasz A, Gutierrez-Adan A (2011) Effect of long-term culture of mouse embryonic stem cells under low oxygen concentration as well as on glycosaminoglycan hyaluronan on cell proliferation and differentiation. Cell Prolif $\quad 44: 75-85 . \quad$ doi:10.1111/j.1365-2184.2010.00732.x; $\quad 10.1111 / \mathrm{j} .1365-$ 2184.2010.00732.x

Richardson RS (1998) Oxygen transport: air to muscle cell. Med Sci Sports Exerc 30:53-59

Roy S, Khanna S, Bickerstaff AA et al (2003) Oxygen sensing by primary cardiac fibroblasts: a key role of p21(Waf1/Cip1/Sdi1). Circ Res 92:264-271

Rudnicki MA, Le Grand F, McKinnell I, Kuang S (2008) The molecular regulation of muscle stem cell function. Cold Spring Harb Symp Quant Biol 73:323-331. doi:10.1101/sqb.2008.73.064

Santilli G, Lamorte G, Carlessi L et al (2010) Mild hypoxia enhances proliferation and multipotency of human neural stem cells. PLoS One 5:e8575. doi:10.1371/journal.pone.0008575

Sato K, Saida K, Yanagawa T, Fukuda T, Shirakura K, Shinozaki H, Watanabe H (2011) Differential responses of myogenic $\mathrm{C} 2 \mathrm{C} 12$ cells to hypoxia between growth and 
muscle-induction phases: growth, differentiation and motility. J Phys Ther Sci 23:161169.

Seale P, Ishibashi J, Holterman C, Rudnicki MA (2004) Muscle satellite cell-specific genes identified by genetic profiling of MyoD-deficient myogenic cell. Dev Biol 275:287-300

Semenza GL (1999) Perspectives on oxygen sensing. Cell 98:281-284

Stamati K, Mudera V, Cheema U (2011) Evolution of oxygen utilization in multicellular organisms and implications for cell signalling in tissue engineering. $\mathrm{J}$ Tissue Eng 2:2041731411432365. doi:10.1177/2041731411432365

Studer L, Csete M, Lee SH et al (2000) Enhanced proliferation, survival, and dopaminergic differentiation of CNS precursors in lowered oxygen. J Neurosci 20:7377-7383

Warkentin KM (2002) Hatching timing, oxygen availability, and external gill regression in the tree frog, Agalychnis callidryas. Physiol Biochem Zool 75:155-164. doi:10.1086/339214

Weidemann A, Johnson RS (2008) Biology of HIF-1alpha. Cell Death Differ 15:621627. doi:10.1038/cdd.2008.12

Yablonka-Reuveni Z, Rivera AJ (1994) Temporal expression of regulatory and structural muscle proteins during myogenesis of satellite cells on isolated adult rat fibers. Dev Biol 164:588-603. doi:10.1006/dbio.1994.1226 
Yablonka-Reuveni Z, Rivera AJ (1994) Temporal expression of regulatory and structural muscle proteins during myogenesis of satellite cells on isolated adult rat fibers. Dev Biol 164:588-603. doi:10.1006/dbio.1994.1226

Yun Z, Lin Q, Giaccia AJ (2005) Adaptive myogenesis under hypoxia. Mol Cell Biol 25:3040-3055

Yun Z, Lin Q, Giaccia AJ (2005) Adaptive myogenesis under hypoxia. Mol Cell Biol 25:3040-3055. doi:10.1128/MCB.25.8.3040-3055.2005

Zhou Z, Bornemann A (2001) MRF4 protein expression in regenerating rat muscle. J Muscle Res Cell Motil 22:311-316

Livak KJ and Schmittgen TD 2001 Analysis of relative gene expression data using real time quantitative PCR and 2- $\square \square \mathrm{C}$ T method. Methods 25 402-408. 